\title{
The man who loved to count and the incredible story of the 35 camels
}

\author{
Marcio Luis Ferreira Nascimento (D) ${ }^{\mathrm{a}, \mathrm{b}}$ and Luiz Barco ${ }^{c}$ \\ Q1 ${ }^{a}$ Department of Chemical Engineering, Polytechnic School, Federal University of Bahia, Salvador, Brazil; ' Institute of Humanities, Arts and \\ O2 Sciences, Federal University of Bahia, Salvador, Brazil; 'School of Communication and Arts, University of São Paulo, São Paulo, Brazil
}

\begin{abstract}
5
\section{Introduction}

According to legend, Malba Tahan - whose complete name was Ali Iezid Izz-Edim Ibn Salim Hank Malba Tahan - was an Arab writer who was translated into

20 Portuguese for Brazilian readers [19,17]. However, in the first of many curiosities associated with Tahan, his translator, Breno Alencar Bianco, never existed. An interview with the author who wrote under the pseudonym of Malba Tahan revealed that Malba means 'oasis'

25 and Tahan means 'miller' (of cereal grain) [5]. His short pieces were moral tales and beautiful stories written in an Arabian style that often touched on mathematical themes.

These writings were a huge success, and in 1938,

30 Tahan published The Man Who Counted (O Homem que Calculaya) [6], which remains in print in Brazil to this day and has been translated into many languages. Two years later, The Man Who Counted was awarded a prize from the prestigious Brazilian Academy of Letters 35 (Figure 1).

The story is about a traveller, Beremiz Samir, a Persian mathematician, who joins the narrator on a voyage that covers dozens of chapters. On the way our hero elucidates problems using his skills and abilities with num-

40 bers, puzzles and curiosities. We present a brief overview of the real man who wrote under the pen name of Malba
Tahan - a Brazilian mathematics professor, engineer, storyteller and writer named Julio Cesar de Mello e Souza (1895-1974) - and celebrate the 120th anniversary of his birth. We also reveal the origins, and discuss a related controversy, of one of his most well-known problems: the riddle of the 35 camels. We show all the 22 possible ways of dividing the inheritance of $t$ jamals (camels) among three brothers - allotting each brother a fraction of the total - that would permit the introduction of one, and the subsequent removal of two camels. More specifically, the division of $t$ camels allots $1 / a$ camels to the older brother, $1 / b$ to the middle brother and $1 /$ $c$ to the younger brother, with integers $a, b$, and $c$ satisfying $a \leq b \leq c \leq t$, and the solutions would provide two remaining camels, after adding just one to the herd. At the end of this paper, we prove that, in addition to being a figure of legend, Malba Tahan really existed.

\section{The Man Who Counted and its author}

Since its first publication in 1938 [6], The Man Who Counted has been an enormously popular book in Brazil and around the world among both mathematics teachers and general readers. The book is rich in references to Islamic traditions and beautiful locations in the Middle East and it transports the reader into a magical world 


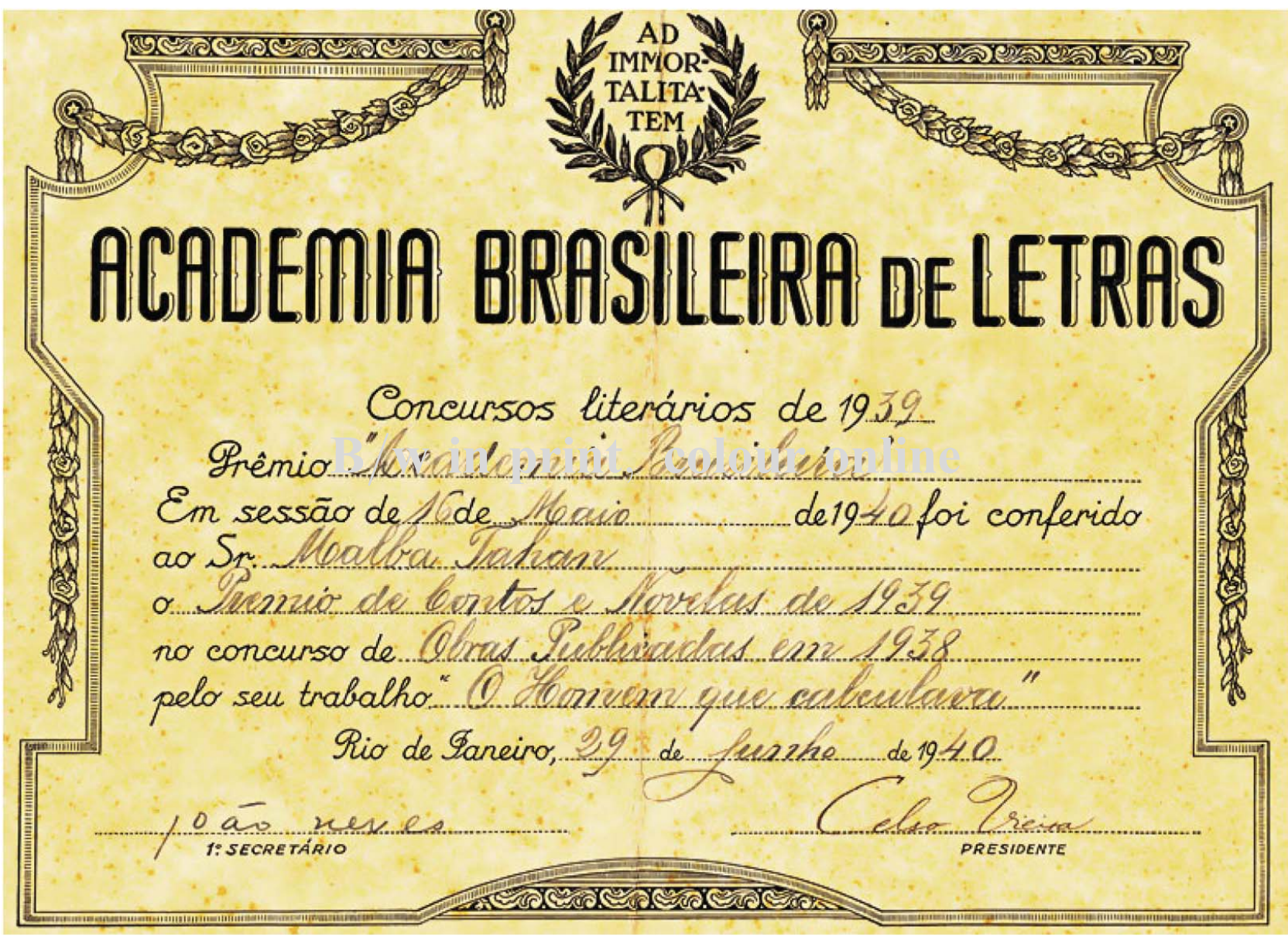

Figure 1. Brazilian Literary Academy prize for The Man Who Counted (O Homem que Calculava). This prize was awarded by the prestigious Brazilian Academy of Letters (Academia Brasileira de Letras, www.academia.org.br). The certificate reads: '1939 Literary Contests; Brazilian Academy Award. In the May 16, 1940 session, Mr. Malba Tahan was conferred the 1939 Tales and Novels Award for writings published in 1938 for his work "The Man Who Counted." Rio de Janeiro June 29, 1940.'

Source: www.malbatahan.com.br.

filled with Bedouins, sheiks, viziers, caliphs, kings, queens, princes and princesses. The mathematical ideas are simple, gentle, interesting, curious and accessible and they drive each story. Arithmetic and geometric

70 puzzles abound. Beremiz, the main character, is blessed with a great ability for calculation and elucidates problems in mathematics and logic in a wide variety of intricate circumstances with great simplicity, talent and precision.

75 This book narrates appealing adventures full of magic, many of which are inspired by Arab legends and tales - with myriad references to common terms and expressions in Arabic, such as Allahu Abkar! ('Allah is the Greatest!'), Maktub ('It is written') and Salaam Alai-

80 kum ('Peace to you') - and by traditional teachings in Arab culture.

Tahan was born on 6 May 1885, 10 years before Mello e Souza [18]. However, the book is sometimes considered a literary hoax because Malba Tahan was a product 85 of the imagination of Julio Cesar de Mello e Souza - although Tahan later became a person, as will be shown below. Mello e Souza was an engineer and mathematics professor from Rio de Janeiro, Brazil, who never set foot in the Middle East.

Born on 6 May 1895, Mello e Souza chose to teach mathematics after completing his engineering degree at college, and he wrote short stories in his spare time $[5,6]$. He was a professor of civil engineering at the University of Brazil, now the Federal University of Rio de Janeiro (www.ufrj.br). In 1918, the first of his stories was submitted to and rejected by the local newspaper, ' $\mathrm{O}$ Imparcial' ('The Impartial') [5]. Later, he was widely published in Brazil and his columns and recreational books typically took the form of a series of tales - à la The Thousand and One Nights - revolving around mathematical puzzles, riddles and curiosities.

However, it is interesting that Mello e Souza's first attempts to publish his writings were neither easy nor successful, according to an interview recorded at the Image and Sound Museum in the city of Rio de Janeiro 
(www.mis.rj.gov.br) [5]. Following these initial failures, Mello e Souza decided to change the names and places in his stories, and he resubmitted them to the same newspaper as translations of the 'incredible' American

110 writer R. S. Slady, one of the author's first pseudonyms. Under this guise, the newspaper printed these first five stories - and on the front page!

After this experience Mello e Souza realized that his best chance of success as a writer in Brazil was to use an

115 Arab pseudonym because, according to Mello e Souza, Arabs had been renowned as great storytellers for centuries [5], including the aforementioned The Thousand and One Nights. Thus, his love of mathematics led to Mello e Souza's fascination with Islamic art and science,

120 and he decided to write stories about ancient Arabia under the nom de plume of 'Malba Tahan.' This pen name was first used in the Rio de Janeiro newspaper 'A Noite' ('The Night') in a fictitious biography that was translated by the previously discussed and equally ficti-

125 tious Breno Alencar Bianco. Both the author and translator were the fruit of the prodigious imagination of Mello e Souza, who gave them life - and gave the newspaper literary production - in a column entitled 'Tales of Malba Tahan' [5].

130 Mello e Souza produced a detailed and sophisticated biography for Malba Tahan. Born in the city of Muzalit, close to Mecca [5,6], Tahan was rich, having inherited money from his father, a successful wine salesman who died in 1912. He was educated in the social sciences and

135 was a teacher and writer who lived in - and later became mayor of - the city of El Medina. Subsequently, Tahan travelled the world, visiting a wide yariety of countries, including Russia, China, England, India and Japan. He spent his last days fighting for the freedom of a group of

140 Bedouins in the desert in July of $1921[5,18]$.

As a teacher, Mello e Souza was critical of the educational methods used in Brazilian classrooms, particularly those used for mathematics $[21,22]$. One of us was fortunate enough to have experienced some lectures by Prof.

145 Mello e Souza on the teaching of mathematics at São Paulo in the 1960s. He was frequently asked to lecture all over Brazil and gave more than 2000 such lectures [5], in which he was consistently simple, gentle, motivating and brilliant.

150 Mello e Souza recognized that one of the greatest difficulties in teaching mathematics is the absence of truly meaningful contexts in which students can build connections to the subject matter. Thus, it is difficult to produce original stories based on mathematics that are

155 interesting to general readers, primarily because many of these readers have different ideas regarding the meaning of mathematics [7]. Notably, classrooms across the globe continue to use Tahan's works as pedagogical tools [23].
For example, Wilder et al. [23] proposed an integrated project that merged the teaching standards of mathematics, social studies and language arts while using technology as the means for an innovative learning medium for high school students. The product of their efforts, known as 'The Man Who Counted' project, drew inspiration from Tahan. Another interdisciplinary project, this one in Portuguese, was proposed and presented by de Faria [5].

\section{The riddle of the 35 camels and similar problems}

In the first occurrence along their journey (Chapter 3 of 170 The Man Who Counted [19,17], 'Beasts of burden'), Beremiz put an end to a heated inheritance quarrel between three brothers in the middle of the desert:

"We are brothers," the oldest explained, "And we received thirty-five camels as our inheritance. According to the express wishes of my father half of them belong to me, one-third to my brother Hamed, and one-ninth to Harim, the youngest. Nevertheless we do not know how to make the division, and whatever one of us suggests the other two disputes. Of the solutions tried so far, none have been acceptable. If half of 35 is 17.5 , if neither one-third nor one-ninth of this amount is a precise number, then how can we make the division?"

The brothers' father had passed away leaving them 35 camels, of which one-half (17.5 camels) were supposed to go to the eldest son, one-third $(11.666 \ldots$ camels $)$ to the middle son and one-ninth $(3.888 \ldots$ camels $)$ to the youngest son. The brothers disagreed about how to divide the inheritance because they did not want to cut up living and beautiful jamals. To solve the brothers' dilemma, Beremiz convinces his friend (not without complaint) to donate his only camel to the dead man's estate to help to solve the riddle. Then, with 36 animals, Beremiz gives the oldest, middle and youngest brothers 18,12 and 4 camels respectively, which means that they all profit from the new distribution. Of the remaining two animals, one was given back to the friend of Beremiz who had donated it, and the other was claimed by Beremiz as his reward for finding a solution.

The translator's endnotes in Portuguese [19] observe that a variant of this problem, with 17 camels to be divided in the same proportions, is found in hundreds of recreational mathematics books, such as those of Gaston Boucheny (1865-1935) [3] and Émile Fourrey (1869-c. 1925) [9], which are in fact cited by Tahan/Bianco. Karl Fink (1851-1898) also published such a problem [8]. However, the 17-camel version leaves only one animal at the end and there is no benefit for the estate executor as 
a consequence. There are more references to this mathe210 matical problem than to the 35 -camel version $[13,14]$.

A widespread version of 'The 17 Camels' is also called the 'One Half + One Third + One Ninth problem' in the history of mathematics. This problem was originally solved by dividing the camels in the proportion 1/2: $1 /$

$2153: 1 / 9$, and the fact that the fractions did not add up to 1 was mostly ignored. Similar fractional problems (but with the sum equal to one) occur in texts from as early as the Rhind Papyrus dated to 1550 BC, now at the British Museum (www.britishmuseum.org).

220 The 17-camel problem is well known in Europe and is allegedly of Arab-Islamic origin [1]. Some authors $[13,14]$ cite Niccolo Fontana Tartaglia $(1500-1557)$ as the first to borrow an 18th animal, which was, in this case, not a camel but a horse. Other notable sources

225 such as Miodrag Petkovic (b. 1948) [12], citing Tartaglia's masterpiece General Trattato (1556) [20], wrote the problem as follows: 'A dying man leaves seventeen horses to be divided among his three sons in the proportions 1/2: 1/3: $1 / 9$. Can the brothers carry out their

230 father's will?' Unfortunately, it was not possible to find such a problem in the monumental works of Tartaglia, in which other inheritance-related problems can be found, in addition to financial problems, some involving horses, such as in books X (Chapter III, problem 5), XII

235 (Chapter I, problem 57) and XVI (Chapter I, problem 77) of the first book [20]. Similar problems are also found in publications by Barry Clarke $(b .1959)$ [4], The Mathematical Monthly [2], and there is even the problem of 17 elephants attributed to Wiljalba Frikell

240 (c. 1818-1903) [10]. However, no similar problem has been found in any older mathematics book. Some sources indicate that in approximately $1202 \mathrm{AD}$, Leonardo Pisano (or Fibonacci, $c$. 1170-c. 1250) [15] wrote something on this topic in his Liber Abaci, but nothing has

245 been confirmed by such references. Nothing similar was found even in existing versions of the first algebra book, written around $820 \mathrm{AD}$ by the Persian mathematician and astronomer Abu Ja'far Muhammad ibn Musa AlKhwarizmi (c. 780-c. 850), called 'Al-kitāb al-mukhtașar

250 fì hisāb al-ğabr wa'l-muqābala' [11], to the best of our knowledge. In this particular book there are many examples of divisions relating to inheritance and legacy among relatives that could inspire such a popular story about camels (or horses).

255 We, thus, agree with Pierre Ageron (b. 1964) [1] about the incorrect and specific Tartaglia citation, which might have been attributed to an ambiguous formulation by Vera Sanford (1891-1971) [13,14]. Some sources attribute the 17 camels problem to the great Ali ibn Abi

260 Talib (c. 600-661), who was a son-in-law and cousin of the prophet Muhammad (c.570-632), and his first
Imam (by Shias) or the fourth Caliph (by Sunnis). In 656, ibn Abi Talib was a commander in the 'Battle of the Camel,' sometimes referred to as the 'Battle of Bassorah' or the 'Battle of Jamal,' in Basra, Iraq in the First Islamic Civil War. Establishing an association of ibn Abi Talib with a 17 camels problem is difficult, although Ageron cites references from the thirteenth to the seventeenth century [1] to support this version.

The 17 camels (or horses) problem is interesting because it is necessary to contrive an artificial method (borrowing an extra animal) to simplify the fractional calculations. Thus, in the resulting calculation, it is possible to divide $17+1$ and obtain $18: 2=9,18: 3=6$ and $18: 9=2$, which means that the sons receive 9,6 and 2 animals. After this division, the borrowed animal is returned to its owner, and the problem is solved.

To the best of our knowledge, Mello e Souza was the first to propose 35 , not 17 , animals to divide in a 'One Half + One Third + One Ninth problem.' He remains famous both in Brazil and around the world for clearly presenting a picture of what can be understood as 'abstract' or even 'pure' mathematics using interesting recreational solutions to a vast set of problems and riddles. In particular, the ' 35 camels problem' can also be consid- 285 ered to be an example of thinking 'outside the box' of mathematics, as Beremiz receives a just reward for solving an inheritance dispute that seems not to have a solution.

In the general case, $n$ animals should be divided among three brothers as $1 / a: 1 / b: 1 / c$, where $a, b$ and $c$ are integers. The question then becomes: Which values of $a, b, c$ and $n$ generate similar problems? It is important here to note that the trick in obtaining an answer is related to the ability to write the sum of the three fractions assigned to the sons as a fraction whose denominator exceeds its numerator by one (in the traditional problem) or by two (in the problem proposed by Tahan). In both cases it is necessary to borrow an extra animal.

For example, Ian Stewart (b. 1945) presents an interesting and broader analysis of the traditional problem [16] that considers other collections of three numbers but permits a similarly curious division of camels and the introduction and subsequent removal of just one extra camel. According to Stewart [16], the unknown Egyptian who wrote the Rhind Papyrus, the Greek mathematician Diophantus of Alexandria (c. 200-c. 284), and even the great Al-Khwarizmi studied such equations at different times.

In essence, Stewart was probably inspired by the style of Mello e Souza's book to write his own particular story [16] because he begins his analysis with a Muslim who was worried about how to share his camels, by the grace of Allah,' and had help from his barber who was also an 'algebrist.' However, the problem considers $d$ camels 
315 and a division into three parts, $1 / a, 1 / b$ and $1 / c$, instead of $1 / 2,1 / 3$ and $1 / 9$, for $d=17+1$ camels, for example (please remember that one was borrowed!). In short, a solution in whole numbers should satisfy the Equation (1):

$$
\frac{1}{a}+\frac{1}{b}+\frac{1}{c}=(d-1) / d
$$

320 In other words, the number $(d-1) / d$ should be expressed as the sum of three reciprocals, which is the same as solving $1 / a+1 / b+1 / c+1 / d=1$. We refer to Equation (1) as 'Mustapha's Equation,' after the patri-

325 arch of Stewart's story. Thus, if $a$ is $2, b$ is 3 and $c$ is 9 , then $d$ must be $18=17+1$, because $1 / 2+1 / 3+1 / 9+$ $1 / 18=1$. There are other solutions for $a, b, c$ and $d$; more specifically, there are 14 different integer solutions to Mustapha's Equation, given that $a \leq b \leq c \leq d$ [16],

330 which Stewart demonstrated using proof by exhaustion. But not all those solutions are relevant in the camel division context. For example, 15 cannot be divided into 2 or 10 , even though $1 / 2+1 / 3+1 / 10+1 / 15=1$. Thus, there is another arithmetic condition: each solution of

335 the equation must be checked to ensure that $d$ is divisible by each of $a, b$ and $c$. Stewart introduced a general argument showing that the number of solutions that exist for this particular problem is finite; we revisit this argument in the Appendix.

340 Applying the same line of thinking to the 35-camel problem, we write 'Tahan's Equation':

$$
\frac{1}{a}+\frac{1}{b}+\frac{1}{c}=(t-2) / t
$$

One solution of this Equation (2) is $a=2, b=3$ and $345 c=9$ and $t=36=35+1$, which would enable the addition of one and subsequent removal of two camels. Again, it is important to note that the three fractions $1 / a, 1 / b, 1 / c$ do not add up to one. Following Stewart's approach, we rewrite 'Tahan's Equation' as

$$
\frac{1}{a}+\frac{1}{b}+\frac{1}{c}+\frac{2}{t}=1
$$

351 Without loss of generality we may assume that $a \leq b$ $\leq c \leq t$, where the right-most inequality is required to ensure that each son receives at least one camel. From

355 Equation (3), it follows that $2 \leq a \leq 5$. To see this, we note that $a \neq 1$, as $a=1$ would make the left side of Equation (3) too large, and $a \geq 6$ would yield a maximum value of the left side of Equation (3) of only $\frac{5}{6}<1$. Similar arguments result in restrictions on $b$ and $c$, specifi-

360 cally, $a \leq b \leq 8$ and $b \leq c \leq 18$. The maximum value for $c$ of 18 is an interesting restriction, which arises by letting $a$ and $b$ be as small as possible, setting $c=t$ and then solving for $c$ in Equation (3). We can then obtain $t$ by solving Equation (3) for $t$ :

$$
t=\frac{2}{1-\frac{1}{a}-\frac{1}{b}-\frac{1}{c}}
$$

Table 1 shows all the 28 possible (positive) integer 366 solutions for Tahan's Equation when $a \leq b \leq c \leq t$. From these 28 solutions, 22 are relevant in the camel division context, because they respect the arithmetic condition that $t$ should be a multiple of $a, b$ and $c$. The solutions were obtained using the restrictions above on $a, b$ and $c$, and Equation (4) for the calculation of $t$.

Please see the Appendix for a general, systematic approach for solving such problems, in which any number of brothers are bequeathed camels in any proportion. The approach shown there can be used to find solutions by hand, and also lends itself readily to implementation as a computer algorithm. Using the notation of the Appendix, Tahan's 35-camel problem is of the form $(1,380$ $1,1,2 ; 1)$

\section{Conclusion or final comments}

The Man Who Counted is delightful on two counts: it features lively recreational mathematics problems, and it is wonderfully written. The book was a bestseller and turned Malba Tahan into a household name, thus making him the most famous Brazilian mathematics professor of all time. He wrote 69 books, including 51 on recreational math and the remainder on other subjects, and had sold more than 2.6 million copies by 1995 [5]. More about Tahan and his works can be found at www.malbatahan. com.br. His most famous book, The Man Who Counted, saw its 86th edition in 2014 in Brazilian Portuguese.

Mello e Souza suffered from heart attack and died in 1974 in the north-eastern Brazilian state of Pernambuco, where he was giving one of his many highly sought after talks.

The Man Who Counted has been translated into Greek, Spanish, Catalan, English, Dutch, Japanese, Korean, French, Serbian, Croatian, German, Arabic and Italian, and it is recommended as a paradidactic source in many of these countries. Mello e Souza earned first prize for Tales and Novels from the prestigious Brazilian Literary Academy in 1940 for his most popular work, as shown in Figure 1. In Brazil, National Mathematics Day is held every May 6th in his honour, according to Brazilian Law Project 3.482-E.

The 17 camels problem follows Muslim traditions, and Mello e Souza recognized his inspiration [17], using a different way and considering 35 camels, which 410 
Table 1. Tahan's Equation, $1 / a+1 / b+1 / c=(t-2) / t$, has exactly 28 solutions for $a, b, c$ and $t$ positive whole numbers and $a \leq b \leq c$ $\leq t$. This table is inspired by Stewart's tree - the process he followed to analyse the Mustapha Equation [16]. Solutions marked with an asterisk $\left({ }^{*}\right)$ do not obey the arithmetic condition that $t$ should be a multiple of $a, b$ and $c$. Thus, we have 22 relevant solutions for this problem, which results in two camels left over after the division when only one is borrowed beforehand. For example, the situation described in Tahan's book considers $a=2, b=3$ and $c=9$ and $t=36$ (the third line of the table).

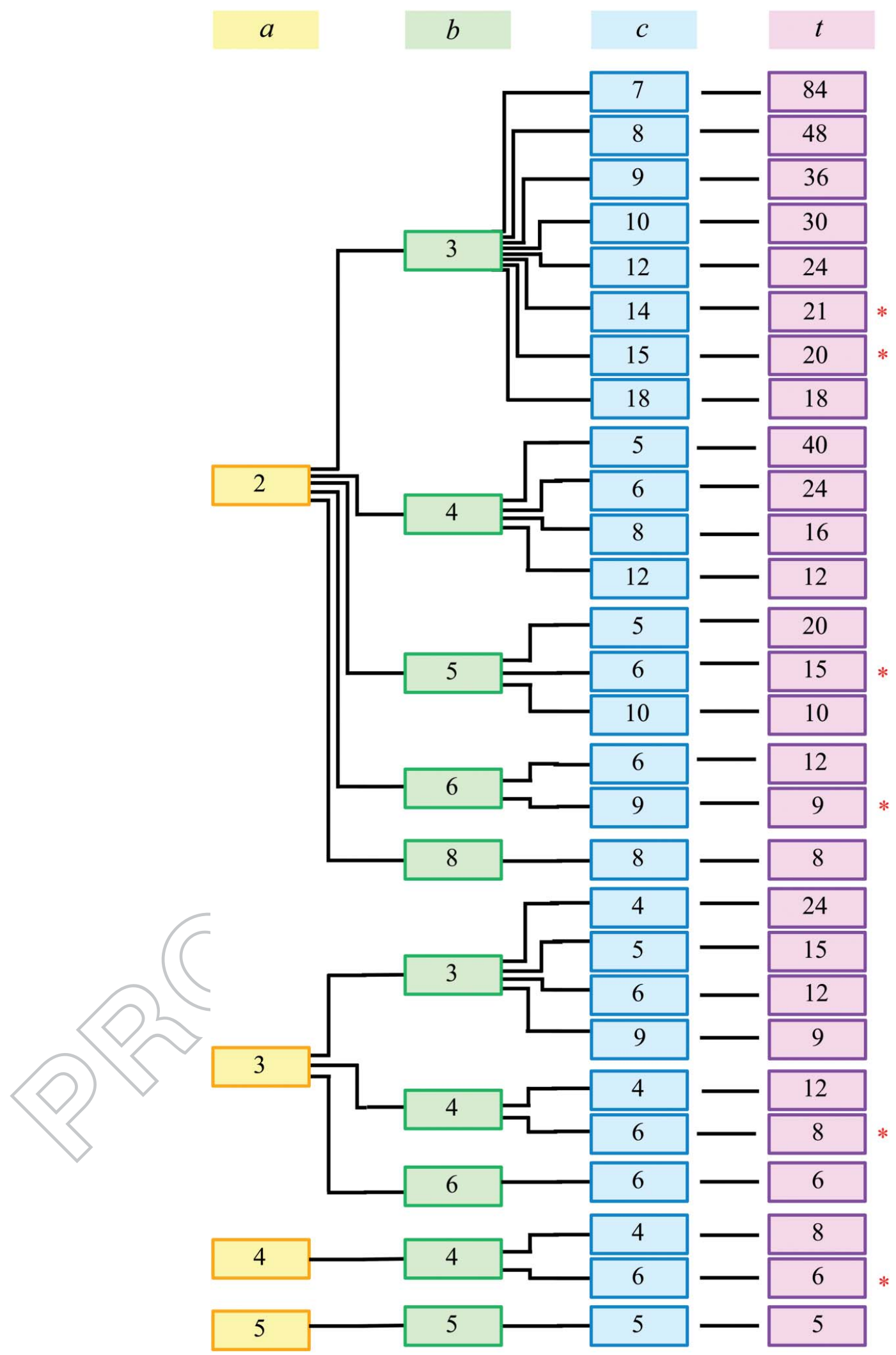




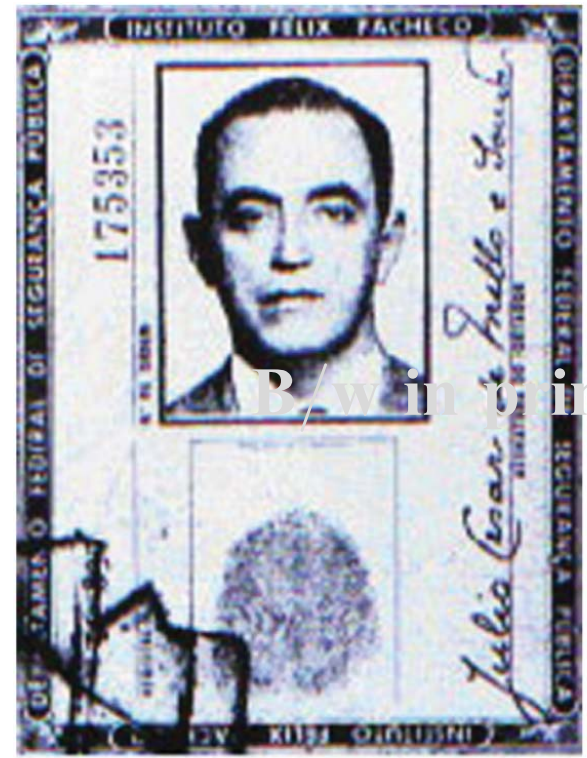

Front

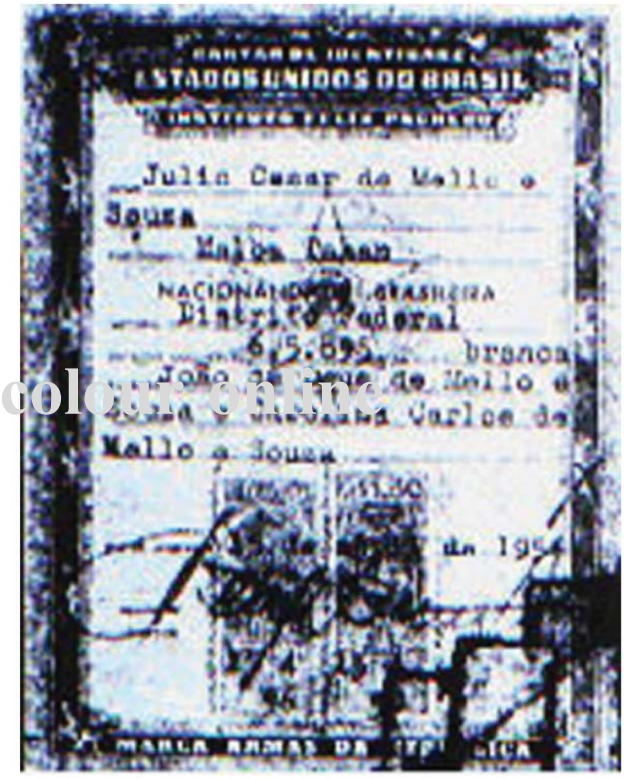

Back

Figure 2. The 1954 Brazilian identity card of Julio Cesar de Mello e Souza. This card served as official identification in Brazil at that time. The front has a picture, unique number $(175,353)$, right thumbprint and signature. The back contains Mello e Souza's full name, the card's expiration date, name of his parents, place (town, state) of birth, date of birth and certain optional information. Below his name is the pseudonym 'Malba Tahan.' Recently, the Brazilian identity card layout was slightly modified and simplified, and there is no longer any way to indicate a nickname, among other changes. Source: www.malbatahan.com.br.

resulted in a small gain of two jamals in exchange for borrowing just one camel. We agree with Stewart [16] that in this beautiful problem 'the psychology of the puzzle is almost as fascinating as the mathematics.' There

415 are in fact 22 integer solutions for this problem when considering $a \leq b \leq c \leq t$ and leaving two animals, as has been demonstrated.

Finally, it is almost a falsehood to maintain that Malba Tahan is only a nickname used by Mello e Souza.

420 Due to his great popularity and because there were four Malba Tahans born in Brazil at that time (one named 'Malba Tahan Siqueira), Mello e Souza himself confirmed that the former Brazilian president Getulio Dornelles Vargas (1882-1954) authorized him to add the name to his identity card (printed in 1954) [5], as shown in Figure 2. However, we note that most Brazilians in the 1950s could indicate their pseudonyms on their identity card without any special permission. Thus, from this document, we can confirm that Tahan really existed, 430 quod erat demonstrandum.

\section{Acknowledgements}

The authors thank the Brazilian $\mathrm{CNPq}$ agency contracts 305373/2009-9, 479799/2010-5, 300938/2012-8 and 471546/ 2012-7 for financial support. We also thank the anonymous 435 referee, the associate editor and the editor-in-chief for suggestions that improved the content and presentation of this article, including another way to get the same mathematical solutions and the Appendix. The authors gratefully acknowledge the granting of reprint permission for the following:

'Beasts of burden,' Chapter 3. Reprinted from The Man Who Counted: A Collection of Mathematical Adventures by Malba Tahan. Copyright (c) 1972 by Helio Marchial de Faria Pereira. Translation copyright (c) 1993 by Leslie Clark and Alastair Reid. With permission of the publisher, W. W. Norton \& Company, Inc. All rights reserved.

\section{Disclosure statement}

No potential conflict of interest was reported by the authors.

08

\section{Funding}

Brazilian CNPq [grant number 305373/2009-9], [grant number 479799/2010-5], [grant number 300938/2012-8], [grant number 471546/2012-7].

\section{ORCID}

Marcio Luis Ferreira Nascimento (D) http://orcid.org/00000001-5030-7500

References

[1] P. Ageron, Le Partage des Dix-Sept Chameaux et Autres Exploits Arithmetiques Attribues á L'Imam Ali: 
Mouvance et Circulation de Recits de la Tradition Musulmane Chiite, [The division of the seventeen camels and other arithmetical achievements ascribed to Imam Ali: alteration and circulation of narratives from the Shia Islamic tradition]. Rev. d'Hist. Math. 19 (2013), pp. 1-41 (in French).

Q11

465

Q12

Q13

470
[2] Anonymous, Notes and queries, in The Mathematical Monthly R.J. Runkle, ed.,Vol. 1, 1859, pp. 362.

[3] G. Boucheny, Curiosités et Récréations Mathématiques, Librairie Larousse, Paris, 1939, pp. 148.

[4] B.R. Clarke, Puzzles for Pleasure, Cambridge University Press, 1994, pp. 10.

[5] J. Conceição de Faria, A Prática Educativa de Júlio César de Mello e Souza Malba Tahan: um Olhar a partir da Concepção de Interdisciplinaridade de Ivani Fazenda, [The educative Practice of Júlio César de Mello e Souza Malba Tahan: a point of view from the conceptions of Ivani Fazenda). PhD. diss., Universidade Metodista de São Paulo, 2004) (in Portuguese).

[6] C. Coppe de Oliveira, A Sombra do Arco-Íris: Um Estudo Histórico/Mitocrítico do Discurso Pedagógico de Julio Cesar de Mello e Souza e mais conhecido como Malba Tahan, (The shadow of the rainbow: a historical/mitocritical study of Malba Tahan' pedagogical discurse). Ph.D. diss., Universidade de São Paulo, 2008 (in Portuguese).

[7] M.L. Ferreira Nascimento and L. Barco, How does mathematics look to you? Educ. Canada 47 (2007), pp. 66-68.

[8] K. Fink, Brief History of Mathematics. Open Court Publishing Company, 1900, pp. 34.

[9] E. Fourrey, Récréations Mathématiques, Vuibert, Paris, 1949, pp. 159.

[10] W. Frikell, in Hanky Panky: A Book of Conjuring Tricks, W. H. Cremer, ed., London, 1872.

[11] M.I. Musa (Khowarezm), in The Algebra of Mohammed ben Musa, Frederick Rosen ed., Oriental Translation Fund, London, 1831.

[12] M.S. Petkovic, Famous Puzzles Great Mathematicians, American Mathematical Society, 2000,pp. 24.

[13] V. Sanford, The History and Significance of Certain Standard Problems in Algebra, Columbia University Press, New York, 1927, pp. 87.

[14] V. Sanford, A Short History of Mathematics, Houghton Mifflin, New York, 1930.

[15] L. Sigler, Fibonacci's Liber Abaci: A Translation into Modern English of Leonardo Pisano's Book of Calculation (Sources and Studies in the History of Mathematics and Physical Sciences), Springer, 2003.

[16] I. Stewart, The riddle of the vanishing Camel. Mathematical recreations, Sci. Am. 266 (1992), pp. 122-124. doi:10.1038/scientificamerican0692-122.

[17] M. Tahan, The Man Who Counted: A Collection of Mathematical Adventures (original Portuguese title: O Homem que Calculava), (Translated by Leslie Clark and Alastair Reid). W. W. Norton \& Company, 1993.

[18] M. Tahan, in Lendas do Oásis, Record, ed., 1999, pp. 7-8 (in Portuguese).

[19] M. Tahan, in O Homem que Calculava, Record, ed., 2001 (in Portuguese).

[20] N.F. Tartaglia, General Trattato di Numeri et Misure ['General Treatise on Number and Measure'], Vol. 6, 1556 (in Italian).
[21] W.R. Valente, Controvérsias sobre Educação Matemática no Brasil: Malba Tahan versus Jacomo Stávale [Controversies about mathematics education: Malba Tahan versus Jacomo Stávale]. Cadernos de Pesquisa 120 (2003), pp. 151-167 (in Portuguese).

[22] W.R. Valente, Mello E Souza e a Crítica aos Livros Didáticos de Matemática: Demolindo Concorrentes, Construindo Malba Tahan, [Mello e Souza criticisms to mathematics textbooks: demolishing competitors, building Malba Tahan). Rev. Bras. Hist. Matemática. 4 (2004), pp. 171-187 (in Portuguese).

[23] S. Wilder, A. Lang, and M. Monegan, The Man Who Counted: a Collection of Integrated Adventures, Teaching Math. App. 34 (2015) pp. 102-114. doi: 10.1093/teamat/ hru023

\section{Appendix}

Let us generalize this class of camel division problems to any number of brothers. We assume that there are $k$ brothers, and that the $i$ th brother desires some fraction $1 / t_{i}$ of the camels, where $t_{i}$ is a positive integer. Without loss of generality we may assume that $t_{1} \leq t_{2}$ $\leq \cdots \leq t_{k}$, because any additional solutions would be permutations of those we find when the $t_{i}$ are nondecreasing.

In the story, Beremiz borrows one additional camel and has two left over after division. More generally, we assume that he borrows $b$ additional camels, allocates every brother an integer share $(t+b) / t_{i}$ of the total, and is left with some final number $r$ of camels to distribute as he wishes. We can express this process in the following equation:

$$
\frac{t+b}{t_{1}}+\cdots+\frac{t+b}{t_{k}}+r=t+b
$$

Our goal is to find, for a given $r$ and $b$, the set of all 551 integer values $t_{1} \leq \cdots \leq t_{k} \leq t$ that satisfy the equation.

Note that $t$ and $b$ always appear added together. Informally, it does not matter whether Beremiz starts with 35 camels and borrows 1, or starts with, say, 32 camels and borrows 4; only the sum $t+b$ affects the solution set. Thus we may as well assume $b=0$. With that assumption, and dividing by $t$, we obtain:

$$
\frac{1}{t_{1}}+\cdots+\frac{1}{t_{k}}+\frac{r}{t}=1
$$

We will find all integer solutions to an equation that generalizes the one above. Let $n_{1}, \ldots, n_{k}$ be any positive integers, and let $0<m \leq 1$ be a rational number. We wish to find all sets of positive integers $t_{1} \leq \cdots \leq t_{k} \quad 565$ 
such that

$$
\frac{n_{1}}{t_{1}}+\cdots+\frac{n_{k}}{t_{k}}=m
$$

We use the notation $\left(n_{1}, \ldots, n_{k} ; m\right)$ to refer to such a 570 problem. With a bit of rearrangement, we can see that the original One Half + One Third + One Ninth problem is one solution to the underlying $(1,1,1,1 ; 1)$ problem, and Tahan's version with two borrowed camels takes the form $(1,1,1,2 ; 1)$.

575 As Stewart noted [16], we can see that there are only finitely many values of $t_{1}$ that could possibly arise in a legal solution. Certainly we must have $n_{1} / t_{1} \leq m$, and so $t_{1} \geq n_{1} / m$. Furthermore, note that $t_{i} \geq t_{1}$ for all $i$, meaning that $n_{i} / t_{i} \leq n_{i} / t_{1}$. Thus we must have

$$
m=\frac{n_{1}}{t_{1}}+\cdots+\frac{n_{k}}{t_{k}} \leq \frac{n_{1}+\cdots+n_{k}}{t_{1}},
$$

581 from which it follows that $t_{1} \leq\left(n_{1}+\cdots+n_{k}\right) / m$. There are therefore only finitely many values of $t_{1}$ that we need to check between these lower and upper bounds. But note that for any given value of $t_{1}$, the remaining $t_{i}$ must satisfy a simpler problem of the form $\left(n_{2}, \ldots, n_{k} ; m-\right.$ $n_{1} / t_{1}$ ). Thus we may conclude that there are only finitely many choices for every $t_{i}$ in this process, and finitely many possible solutions overall.

Furthermore, this argument immediately suggests a recursive procedure for finding all solutions: first consider all legal values of $t_{1}$, then for each such value consider all possibilities for $t_{2}$, and so on. Stewart expressed the solutions arising from this recursive procedure in the form of a tree [16], similar to the one shown in Table 1, 595 starting with $a=t_{1}=2$. Of course, under the very reasonable assumption that individual camels cannot be further subdivided, we must check each of these solutions to ensure that they satisfy the "arithmetic condition" mentioned in the paper, namely that $t_{i}$ divides $t$ for 600 all $i$. 